\title{
The Association Between Medical Diseases and Late-Life Depression: The Presence, Number, and Type of Medical Diseases
}

\author{
ID Emre Senol-Durak ${ }^{1}$ ID Mithat Durak
}

\begin{abstract}
Medical diseases are highly prevalent among older adults and lead to several changes in psychosocial life. One effect of those problems is seen on depression. On the other hand, whether the type or the number of medical diseases are associated with late-life depression have not examined in the literature. The aim of the present study is to examine whether the place of residence, type of illnesses or a number of illnesses would make a difference on late-life depression. For this purpose, older adults living at home $(N=1100)$ and nursing home $(N=1177)$ participated in the present study. The Demographic Information Form, including the type and number of medical diseases, and the Geriatric Depression Inventory were applied. Results demonstrated that older adults having two or more medical diseases had higher scores of late-life depression than those with one medical disease and those without suffering any medical disease. Older adults with suffering only psychiatric disease or digestive system disease had a higher level of late-life depression. Besides, older adults having chronic medical diseases had higher scores of late-life depression such as patients with psychiatric disorders, digestive system diseases, cardiovascular system diseases, metabolic and endocrine disorders, rheumatic and musculoskeletal diseases, central nervous system - neurological disorders, urinary system diseases, and sensory system disease. Results were discussed in the light of literature about medical diseases, late-life depression, and caring needs of older adults.
\end{abstract}

Keywords: Older adults, late-life depression, medical diseases, disorders, type of disease, number of physical illness

\section{Key Practitioners Message}

> Older adults with chronic disease experience higher depression than the other ones.

$>$ Developing screening tools among older adults with physical problems are recommended since there are some overlapping symptoms of depression and medical illnesses among patients with medical diseases in late-adulthood.

- Educating doctors about early recognition of depression among older adults are encouraged when dealing with multiple diseases.

$>$ Giving information to older adults about the medical disease is also recommended to handle depression.

One of the psychological disorders seen among older adults is depression. Depression prevalence is noted as $5 \%$ of older adults living at their home, and $42 \%$ of older adults living in long-term care service (Luppa et al., 2012). It is estimated that among half of older adults, the first onset of depression is likely to see in late adulthood (Fiske, Wetherell, \& Gatz, 2009). Depression among older

Correspondence: Emre Senol-Durak. Bolu Abant Izzet Baysal University, Faculty of Arts and Sciences, Department of
Psychology, 1428o, Bolu - Turkey.e-mail: emresenoldurak@gmail.com

Authors: ${ }^{-1}$ Bolu Abant Izzet Baysal University, Department of Psychology

Received: 15 September 2019| Accepted: 23 December 2019| Published Online: 29 December 2019 
adults is also called late-life depression, which is observed as changes in cognitions and somatic complaints mostly (Fiske et al., 2009). However, inadequate empirical evidence is mentioned about somatic complaints and depression relationships in late-life depression (Haigh, Bogucki, Sigmon, \& Blazer, 2018). Besides, psycho-social variables are noted as necessary for late-life depression, which is highly seen among ones being separated and divorced and having no formal education (Subramaniam et al., 2016; Lue et al., 2010). Similarly, higher education and lower late-life depression are reported (Fiske et al., 2009; Zivin et al., 2010). Also, loneliness and lower social support effect depression scores of older adults who have medical diseases (Fiske et al., 2009). In respect to gender, women participants are more likely to suffer more depression than the others (Lue et al., 2010). On the other hand, genetic markers of medical diseases are reported to affect men more than women in the case of depression (Petkus et al., 2017). Similarly, it is mentioned that stressful life events affect aged men more than women (Forlani et al., 2014). Therefore, controversial results appear in the relationship between gender and late-life depression. Besides, researchers question whether latelife depression is different from depression in adulthood. The prognosis of depression in late adulthood is different from other life periods that relapse is more likely to see due to the effect of medical diseases (Haigh et al., 2018). Also, it is highlighted in the literature that difficulties related to medical diseases combine with challenges about aging that lead to difficulty evaluate depression (Saracino, Rosenfeld \& Nelson, 2016). Therefore, examining medical disease and depression relationship is essential to reveal the nature of late-life depression.

Medical diseases are highly prevalent among older adults. Hypertension, cardiac problems, diabetes, sensory problems are some of the commonly seen medical diseases among them. Those health problems affect daily life and lead to several changes in the psycho-social lifecycle. For instance, older adults with diabetes monitor blood glucose levels and dietary in every day and attend sports activities. All of those changes in activities are necessary to regulate medical diseases and include additional energy, which is quite challenging in old age. Also, sleep disturbance problems arise commonly among older adults (Bao et al., 2017; Garfield, Llewellyn, \& Kumari, 2016) whose energy is affected adversely by sleep problems. When older adults have the inability to make psycho-social changes in lifestyle, their difficulty with medical diseases arises since physical and psycho-social life are interconnected. For instance, physical disability and frailty influence individuals (Collard et al., 2017) that older adults having a high functional disability has higher scores of suicidal ideations (Fässberg et al., 2016). It is noted that older adults with severe health problems experience burnout (Boe et al., 2017; Subramaniam et al., 2016) that some of them commit suicide, therefore. Similarly, suicidal behavior is associated with depression and medical diseases in old age (Cheung \& Sundram, 2017). Likewise, higher physical disability and higher depression are more likely to seen among older adults that re-admission to the health care centers and mortality rates are results (Hummel et al., 2017). Similarly, low physical activity and high depression are mentioned to be associated (Mclntyre et al., 2019). Also, medical diseases are revealed to limit social life that affects higher depressive feelings (Petkus et al., 2017). Therefore, it can be concluded that medical diseases, restrictive social life, activity level, and depression are highly related.

In addition to the influence of medical diseases, it is questioned whether there is a difference between types of diseases on depression. In a study inquiring about the type of medical disease, depression is highly seen among older adults with heart problems, diabetes, ischemic attacks, physical impairments (arthritis), asthma, cough, internal disease (stomach or intestine), and paralysis (Subramaniam et al., 2016). Also, depression is seen among older adults with cancer patients (Saracino et al., 2016). In another study, older adults with lung and heart disease problems are reporting higher depression, whereas patients with diabetes, hypertension, and stroke 
reported lower levels of depression (Zivin et al. 2010). Besides, more inadequate health perceptions about medical disease and higher late-life depression are associated with each other (Lue et al., 2010).

Understanding the nature of depression and its relation to weakness in health is crucial among older adults uniquely to define risk factors (Collard et al., 2017). Also, exploring psycho-social factors increasing the incidence of late-life depression is highlighted to be important in prevention (Lue, Chen, \& Wu, 2010). The medical disease and depression relationship are dynamic (Zivin et al. 2010). The bidirectional relationship between health problems and depression among older adults living in different places would help professionals to figure out early intervention strategies. On the other hand, whether the type and number of medical health problems in older adults are associated with late-life depression has not been extensively examined in the literature. Although screening studies have been conducted with older adults who are admitted to hospital or resident in a nursing home, studies with older adults living in their own homes are rarely seen in the literature. The number of studies conducted with large samples is also limited.

The present study aims to investigate the relationship between late-life depression and the number or type of medical diseases in a large sample of older adults. The aim of this study is to investigate whether late-life depression is related to the number and type of physical illnesses that older adults suffer from. In this frame, three hypotheses are tested:

1- Late-life depression levels of older individuals with any medical diseases are higher than healthy older adults.

2- The late-life depression levels of older adults suffering from medical diseases in more than one health category are higher than those having health problems in one health category.

3- The late-life depression level varies according to the type of medical health problem experienced.

\section{Method}

\section{Participants}

The data of the study were collected with 2277 older adults aged 60 and over. The age range ranged from 60 to 100 for older adults ( $M=72.92$, $\mathrm{SD}=8.21)$ and $52.0 \%$ of the participants were men $(n=1183)$ and $48.0 \%$ were women $(n=1094)$. The rate of the participants living in the nursing home is $51.7 \%(n=1177)$ and the percentage of the participants living in their own home is $48.3 \%$ $(n=1100)$. The majority were married $(37.7 \%, n=$ $859)$ and widowed participants $(39.1 \%, \mathrm{n}=890)$; $13.1 \%(n=299)$ of the divorced, $6.7 \%(n=152)$ of the unmarried and $3.4 \%(n=77)$ of the separate.

\section{Measures}

The Demographic and Health Information Form: The form prepared before data collection includes questions to be asked to the participants regarding age, gender, place of residence, marital status, and type or number of diseases/disorders.

The Geriatric Depression Scale (GDS): The Geriatric Depression Scale (GDS) is a 30-item scale developed by Yesavage et al. (1983) to be answered as "yes" and "no" format. Some of the items of the scale are "Are you basically satisfied with your life?", "Are you hopeless about the future?", "Do you feel very sorry about the past? It is a scale that excludes somatic complaints and substances that may cause a reaction in older adult patients with low diagnostic value. Turkish validity and reliability study was conducted by both Ertan et al. (1996) (test-retest consistency, $r=.77$; internal consistency coefficient = .92) and Sagduyu (1997) (test-retest consistency, $r=.87$; internal consistency coefficient $=.72$ ). In this form of the cutting point adapted to Turkey scale 13/14, the sensitivity of this breakpoint .90 . The scale adapted by Sagduyu (1997) was used in the study.

\section{Procedures}

Before collecting the data, researchers received ethical approval from the research board of the university. In order to reach a large sample size, the data of the study were collected from old- 
er adults living at a nursing home or their own homes who were voluntarily involved in the present study. Informed consent was taken before data collection. It took 10-15 minutes to complete the questions.

\section{Data Analysis}

All statistical analyses were conducted by using the SPSS-25 (IBM, Armonk, NY, USA). The p-value threshold used to decide statistical significance was established at 05 .

\section{Results}

\section{Frequencies of the Diseases and Disorders}

Participants were asked whether they experienced diseases or disorders in thirteen medical health problem categories: (1) Respiratory system diseases, (2) cardiovascular system diseases, (3) hematopoietic system diseases, (4) diseases of the digestive system, (5) endocrine and metabolic disorders, (6) urinary system diseases, (7) breast diseases, (8) immune system diseases, (9) dermatological diseases, (10) sensory system diseases, (11) central nervous system disorders / neurological disorders, (12) rheumatic and musculoskeletal diseases, and (13) psychiatric disorders. The six most common categories of diseases in the present study are listed as follows: Cardiovascular system diseases (38.12\%), metabolic and endocrine disorders (15.46\%), psychiatric disorders $(12.38 \%)$, rheumatic and musculoskeletal diseases $(9.00 \%)$, central nervous system / neurological disorders (7.64\%), and respiratory system diseases $(6.98 \%)$. The categories of medical health problems, the diseases or disorders in the categories, and the frequencies of disease categories in the sample of the present study are shown in Table-1.

\section{The Relationship Between the Number of Diseases and Late-Life Depression}

The relationship between the number of diseases and late-life depression was tested by One Way ANOVA. The number of diseases is categorized into three groups: No illness-disorder, one illness-disorder category, two or more illness-dis- order categories. One Way ANOVA test result is significant, $\left[F(2,2274)=71.20, p=1.02^{e-30}\right]$. According to the results of the Bonferroni posthoc comparison, groups are statistically different from each other. The older individuals who report disease from at least two disease categories (two or more illness-disorder group; $M=11.93, S D$ $=7.20, n=502$ ) are more depressed than older individuals who report disease from one disease category (one illness-disorder group; $M=9.88$, $S D=6.94, n=1220)\left(p=3.11^{\mathrm{e}-08}\right)$ and older individuals who do not report any disease (no illness-disorder group; $M=7.03, S D=5.80, n=$ $555)\left(p=1.02^{e-30}\right)$. Moreover, the older individuals who report disease from one disease category (one illness-disorder group) are more depressed than older individuals who do not report any disease (no illness-disorder group) $\left(p=8.92^{\mathrm{e}-16}\right)$. According to these results, the first two hypotheses of the research were accepted. The results of the One-Way ANOVA test are shown in Figure-1.

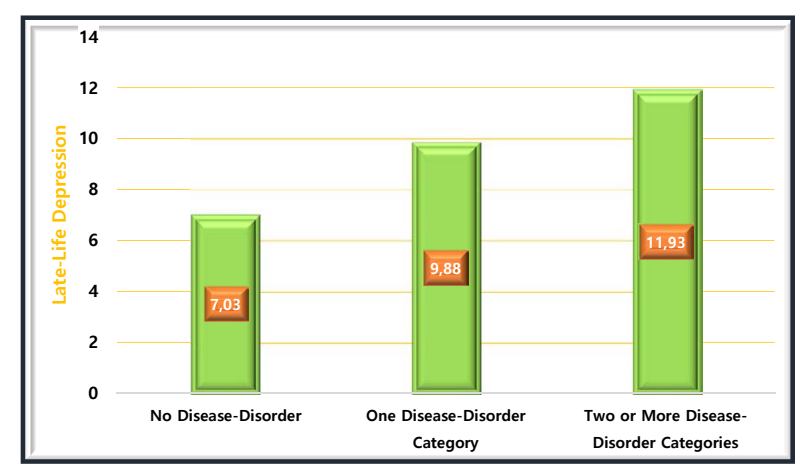

Figure-1. The relationship between the number of diseases and late-life depression

\section{The Relationship Between the Type of Diseases and Late-Life Depression}

The participant numbers, late-life depression means and standard deviations of ten disease categories, except the disease categories of hematopoietic system diseases, breast diseases, and immune system diseases that cannot be investigated because their observed frequencies are low, are shown in Table-2.

Psychiatric disorders are associated with a high level of late-life depression, alone ( $M=12.67, S D$ 
$=7.81)$ or in the presence of other accompanying diseases ( $M=13.86, S D=6.99)$. As expected, depressive symptoms are frequently seen with other psychiatric diseases.

After psychiatric disorders, digestive system diseases are the second category of diseases associ- ated with high levels of late-life depression, alone $(M=11.63, S D=7.89)$ or in the presence of other accompanying diseases $(M=11.98, S D=7.21)$.

The presence of one or more diseases causes many diseases to be associated with high levels of depression among people with cardiovascular

Table-1. The categories of medical health problems

\begin{tabular}{|c|c|c|c|c|}
\hline & $\begin{array}{l}\text { Categories of Medical } \\
\text { Health Problems }\end{array}$ & Medical Health Problems & Frequencies & $\%$ \\
\hline 1. & $\begin{array}{l}\text { Cardiovascular System } \\
\text { Diseases }\end{array}$ & $\begin{array}{l}\text { Rhythm and conduction disorders, coronary artery diseases, vascular } \\
\text { diseases and inflammation, peripheral artery disease, hypertension, etc. }\end{array}$ & 868 & 38.12 \\
\hline 2. & $\begin{array}{l}\text { Metabolic and Endo- } \\
\text { crine Disorders }\end{array}$ & $\begin{array}{l}\text { Diabetes mellitus, elevated cholesterol, graves' disease, Hashimoto } \\
\text { thyroiditis, Addison's disease, goiter, obesity, epiphysis, thyroid, para- } \\
\text { thyroid, thymus, liver, pancreas, intestinal system and other conditions } \\
\text { associated with insufficiency or excess of adrenal gland hormones }\end{array}$ & 352 & 15.46 \\
\hline 3. & Psychiatric Disorders & $\begin{array}{l}\text { Anxiety disorders, depression, bipolar disorder, obsessive-compulsive } \\
\text { disorder, social phobia, panic disorder, obsessive-compulsive disorder } \\
\text { (OCD), post-traumatic stress disorder (PTSD), schizophrenia eating dis- } \\
\text { orders, personality disorders, substance abuse, etc. }\end{array}$ & 282 & 12.38 \\
\hline 4. & $\begin{array}{l}\text { Rheumatic and Muscu- } \\
\text { loskeletal Diseases }\end{array}$ & $\begin{array}{l}\text { Inflammation, infections, and deterioration of muscle, joints, and bones, } \\
\text { rheumatoid arthritis (arthritis), Systemic lupus erythematosus (SLE), etc. }\end{array}$ & 205 & 9.00 \\
\hline 5. & $\begin{array}{l}\text { Central Nervous System } \\
\text { / Neurological Disor- } \\
\text { ders }\end{array}$ & $\begin{array}{l}\text { Paralysis, epilepsy, meningitis, rabies, Alzheimer's, dementia, sleep } \\
\text { disorders, multiple sclerosis (MS), amyotrophic lateral sclerosis (ALS), } \\
\text { Parkinson's, balance disorders, myasthenia gravis, Guillain-Barré Syn- } \\
\text { drome and so on. }\end{array}$ & 174 & 7.64 \\
\hline 6. & $\begin{array}{l}\text { Respiratory System } \\
\text { Diseases }\end{array}$ & $\begin{array}{l}\text { Upper and lower respiratory diseases, acute bronchitis, chronic bron- } \\
\text { chitis, Chronic Obstructive Pulmonary Disease (COPD), pneumonia, } \\
\text { tuberculosis, asthma, lung cancer, and so on. }\end{array}$ & 159 & 6.98 \\
\hline 7. & $\begin{array}{l}\text { Diseases of the Diges- } \\
\text { tive System }\end{array}$ & $\begin{array}{l}\text { Diarrhea, constipation, reflux, indigestion, hemorrhoids, breech frac- } \\
\text { tures (anal fissures), colitis, stomach cancer, bowel cancer, liver can- } \\
\text { cer, gallbladder cancer, pancreatic cancer, esophagus cancer, salivary } \\
\text { gland cancer, gastric ulcer \& bleeding, gastritis problems, gallstones } \\
\text { and inflammations, diseases of the stomach and duodenum, diseases } \\
\text { of the small intestine, diseases of the large intestine, diseases of the } \\
\text { rectum, bleeding from the esophagus varicose veins, stomach and in- } \\
\text { testinal polyps, cirrhosis, etc }\end{array}$ & 112 & 4.92 \\
\hline 8. & $\begin{array}{l}\text { Urinary System Dis- } \\
\text { eases }\end{array}$ & $\begin{array}{l}\text { Kidney infection, bladder infection, infection of other organs of the uri- } \\
\text { nary tract, inflammation of the prostate and other connected organs } \\
\text { (prostatitis), urinary production and excretory system-related disorders, } \\
\text { urinary production and excretory system-related anomalies, urinary pro- } \\
\text { duction and excretory system-related obstructions, stones, malignancies }\end{array}$ & 109 & 4.79 \\
\hline 9. & $\begin{array}{l}\text { Sensory System Dis- } \\
\text { eases }\end{array}$ & $\begin{array}{l}\text { Diseases and disorders related to the sense of sight, hearing, smell, } \\
\text { and taste. }\end{array}$ & 56 & 2.46 \\
\hline 10. & $\begin{array}{l}\text { Dermatological Dis- } \\
\text { eases }\end{array}$ & $\begin{array}{l}\text { Eczema, atopic dermatitis, acne, skin infections through sexual contact, } \\
\text { warts, herpes, shingles, fungal diseases, benign and malignant tumors } \\
\text { of the skin, diseases of the scalp, nail disorders, moles, allergic and } \\
\text { itchy skin diseases, vitiligo, etc. }\end{array}$ & 17 & 0.75 \\
\hline 11. & $\begin{array}{l}\text { Hematopoietic System } \\
\text { Diseases }\end{array}$ & $\begin{array}{l}\text { Leukemias, lymphomas, multiple myeloma, myelodysplastic syndrome, } \\
\text { hemophilia, Mediterranean anemia, pernicious anemia, aplastic ane- } \\
\text { mia, thrombocytopenia, and so on. }\end{array}$ & 12 & 0.53 \\
\hline 12. & Breast Diseases & Breast tissue anomalies, fat tissue loss, ductal obstruction, cysts, cancers & 2 & 0.09 \\
\hline 13. & $\begin{array}{l}\text { Immune System Diseas- } \\
\text { es }\end{array}$ & $\begin{array}{l}\text { Psoriasis, psoriatic arthritis, inflammatory bowel disease (IBD), immune } \\
\text { vasculitis, celiac disease, Sjogren's syndrome, HIV, etc. }\end{array}$ & 0 & 0.00 \\
\hline
\end{tabular}


Senol-Durak \& Durak. Medical Diseases and Late-Life Depression

Table-2. The relationship between the type of diseases and late-life depression

\begin{tabular}{|c|c|c|c|c|c|c|c|c|c|c|c|c|}
\hline & \multicolumn{6}{|c|}{ Presence of the Disease (PD) } & \multicolumn{6}{|c|}{ Absence of the Disease (AD) } \\
\hline & \multicolumn{3}{|c|}{ One Disease Category } & \multicolumn{3}{|c|}{$\begin{array}{c}\text { Multiple Disease } \\
\text { Categories }\end{array}$} & \multicolumn{3}{|c|}{ One Disease Category } & \multicolumn{3}{|c|}{$\begin{array}{c}\text { Multiple Disease } \\
\text { Categories }\end{array}$} \\
\hline & $\mathrm{n}$ & M & SD & $\mathrm{n}$ & M & SD & $\mathrm{n}$ & $\mathrm{M}$ & SD & $\mathrm{n}$ & M & SD \\
\hline Cardiovascular & 512 & 9.17 & 6.55 & 356 & 11.33 & 6.97 & 708 & 10.38 & 7.17 & 146 & 13.40 & 7.55 \\
\hline Endocrine & 151 & 9.39 & 6.73 & 201 & 12.21 & 6.91 & 1069 & 9.94 & 6.97 & 301 & 11.74 & 7.39 \\
\hline Psychiatric & 49 & 12.67 & 7.81 & 233 & 13.86 & 6.99 & 1171 & 9.76 & 6.88 & 269 & 10.25 & 6.96 \\
\hline Musculoskeletal & 118 & 9.70 & 6.93 & 87 & 10.77 & 7.17 & 1102 & 9.89 & 6.94 & 415 & 12.17 & 7.19 \\
\hline Neurological & 117 & 10.63 & 6.99 & 57 & 12.84 & 8.29 & 1103 & 9.80 & 6.93 & 445 & 11.81 & 7.05 \\
\hline Respiratory & 96 & 10.83 & 7.85 & 63 & 9.54 & 6.56 & 1124 & 9.79 & 6.85 & 439 & 12.27 & 7.22 \\
\hline Digestive & 65 & 11.63 & 7.89 & 47 & 11.98 & 7.21 & 1155 & 9.78 & 6.87 & 455 & 11.92 & 7.20 \\
\hline Urinary & 68 & 10.82 & 7.12 & 41 & 12.85 & 7.87 & 1152 & 9.82 & 6.93 & 461 & 11.85 & 7.14 \\
\hline Sensory & 29 & 8.69 & 5.56 & 27 & 11.00 & 7.50 & 1191 & 9.90 & 6.97 & 475 & 11.98 & 7.18 \\
\hline Dermatological & 8 & 7.13 & 3.64 & 9 & 7.00 & 7.35 & 1212 & 9.89 & 6.95 & 493 & 12.02 & 7.17 \\
\hline
\end{tabular}

Note-1. $n=$ number of participants, $M=$ mean, and SD = standard deviation

Note-2. . Disease $=$ Disease or disorder.

Note-2. Since the observed frequencies are low, the hematopoietic system diseases, breast diseases, and immune system diseases are not included.

system diseases, metabolic and endocrine disorders, rheumatic and musculoskeletal diseases, central nervous system - neurological disorders, urinary system diseases, and sensory system diseases. In the presence of another or more diseases, cardiovascular system diseases, metabolic and endocrine disorders, rheumatic and musculoskeletal diseases, central nervous system - neurological disorders, urinary system diseases, and sensory system diseases are related to a high level of late-life depression. Two exceptions to this condition have been observed: Respiratory system diseases and dermatological diseases (see Figure-2).

\section{Discussion}

The present study aimed to explore medical diseases comorbidity with depression among aged adults. Researchers suggested an understanding of the association with medical diseases and depression to define risk factors and prevention strategies (Collard et al., 2017; Lue et al., 2010). This study investigates the role of the type and the number of medical diseases on late-life depression.

In respect to the percentage of diseases or disorders, cardiovascular system diseases, metabol-

Figure-2. Graphical demonstration of the relationship between disease types and late-life depression

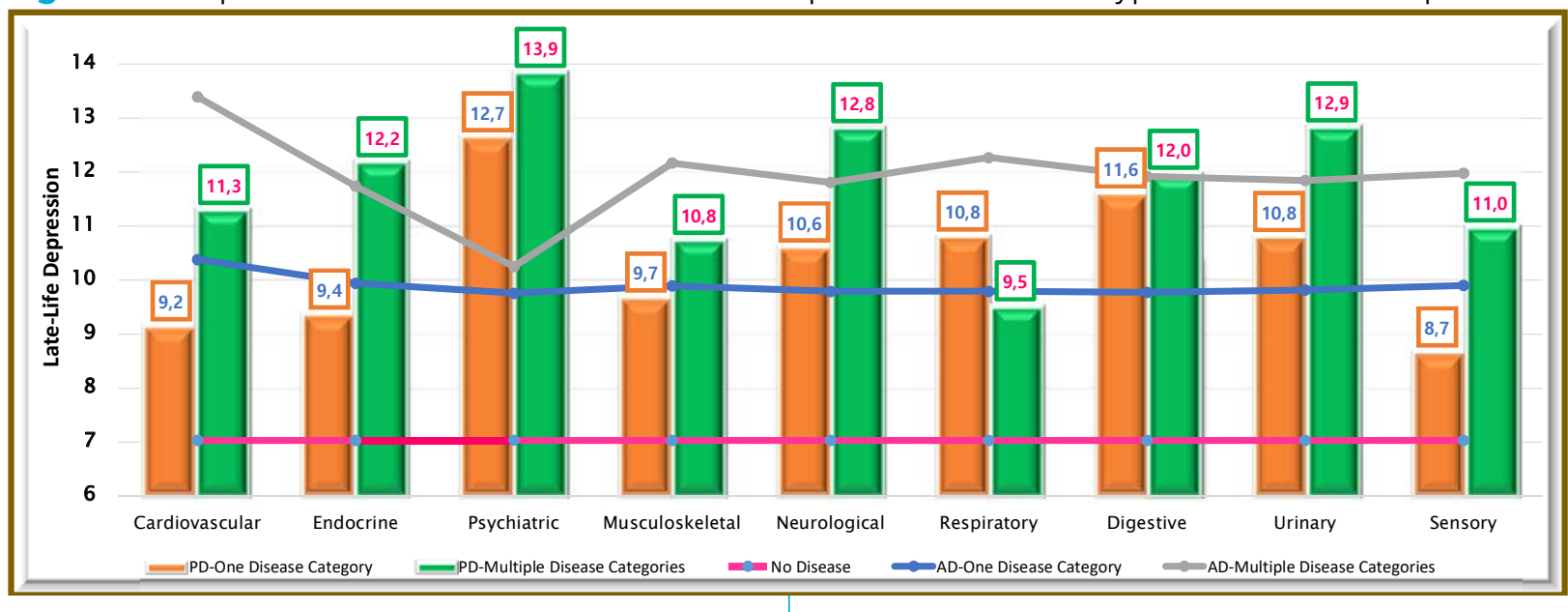


ic and endocrine disorders, psychiatric disorders, rheumatic and musculoskeletal diseases, central nervous system / neurological disorders, and respiratory system diseases are the six most commonly observed categories of diseases. As expected, older adults having two or more medical diseases category has higher scores of late-life depression than those with one medical disease category or those without any medical disease. Individuals exposed to two or more medical disease might experience more boredom than the others when considering burnout and medical disease relationship (Boe et al., 2017; Subramaniam et al., 2016). Those people should adhere to treatment, which is requiring high effort.

Likewise, seen in other studies (Subramaniam et al., 2016), the types of medical diseases are related to late-life depression. In the present study, higher depression is seen among participants who have psychiatric disease and digestive system alone. Since depression is one of the psychiatric disorders, higher depression among patients with any psychiatric disorder is understandable. Patients might feel hopeless and helpless about the treatment of a psychiatric disorder that those symptoms are part of depression. The digestive system is also called the second brain since it supports the immune system for healthy functioning (Lipski, 2012). Therefore, higher late-life depression among patients with digestive diseases is understandable since individuals' capability to digest well is limited, which leads to difficulty in life. Besides, in the case of multiple diseases, patients with psychiatric disorders, digestive system diseases, cardiovascular system diseases, metabolic and endocrine disorders, rheumatic and musculoskeletal diseases, central nervous system - neurological disorders, urinary system diseases, and sensory system disease. Besides, as cited in the literature, older adults with chronic disease experience higher depression (Zivin et al., 2010). Similar findings were seen for higher depression with respiratory and heath disease (Zivin et al., 2010). A possible reason is those problems have restrictive value on the daily life of older adults. For instance, older adults with urinary problems should use restrooms frequently during the day, which limits the life cycle. Also, older adults with metabolic or endocrine system disorder should monitor blood glucose levels and use a restrictive diet every day. Patients with rheumatic and musculoskeletal diseases have the inability to move in places that also limit the level of solid functionality. In case of experiencing multiple diseases, older adults have higher caring needs. Managing the medicine cycle (i.e., taking pills) becomes complicated. Therefore, having more than one chronic disorder and a higher depression relationship is expected.

There are certain limitations to the present study. Association between types of and the number of illness and depression were investigated cross-sectionally. It is recommended to examine whether the time is contributing to results. Therefore, longitudinal studies can help to investigate physical changes in time relation to depression. Also, individuals' ratings about the importance of the disease in their daily life are recommended for future studies in case especially patients with multiple disorders. On a behind of limitations, the present study participants are composed of older adults who are living at a hospital, in a nursing home, or in a home. Also, using a large sample is one of the strengths of the present study.

In clinical settings, developing screening tools among older adults with physical problems are recommended (Saracino et al., 2016; Subramaniam et al., 2016) since there are some overlapping symptoms of depression and medical illnesses among patients with medical diseases in late-adulthood (Haigh et al., 2017; Saracino et al., 2016). Also, collaborations between psychologists and doctors are necessary (Subramaniam et al., 2016). Moreover, it is highlighted to educate doctors about early recognition of depression (Fiske et al., 2009). Also, pharmacological treatment to be less efficacious (Haigh et al., 2017). Therefore, psychological treatment is necessary. Giving information to older adults about medical disease is also recommended to handle depression (Fiske et al., 2009). Besides, as seen in a meta-analysis, encouraging older adults' social support groups (Forsman, Schierenbeck, \& Wahlbeck, 2011) and applying cognitive-behavioral 
psychotherapy treatment (Hummel et al., 2017) are helping to recovery from late-life depression.

Briefly, older adults with chronic medical diseases and late-life depression relationship are revealing the bidirectional functions of the physical and psychological system. Future studies are encouraged to examine those relations between the systems.

Acknowledgment: This study was supported entirely by the Scientific and Technological Research Council (Project No: TUBITAK-SOBAG 110K039).

\section{References}

Bao, Y. P., Han, Y., Ma, J., Wang, R. J., Shi, L., Wang, T. Y., ... \& Lu, L. (2017). Cooccurrence and bidirectional prediction of sleep disturbances and depression in older adults: Meta-analysis and systematic review. Neuroscience and Biobehavioral Reviews, 75, 257-273. Crossref.

Cheung, G. \& Sundram, F. (2017). Understanding the progression from physical illness to suicidal behavior: A case study based on a newly developed conceptual model. Clinical Gerontologist, 40(2), 124129. Crossref.

Collard, R. M., Arts, M. H. L., Schene, A. H., Naarding, P., Voshaar, R. O., \& Comijs, H. C. (2017). The impact of frailty on depressive disorder in later life: Findings from the Netherlands Study of depression in older persons. European Psychiatry, 43, 66-72. Crossref.

Ertan, T., Eker, E., \& Sar, V. (1997). Validity and reliability of the Geriatric Depression Scale in the Turkish elderly population [Geriatrik Depresyon Ölçeğinin Türk yaşlı nüfusunda geçerlilik ve güvenilirliği]. Archives of Neuropsychiatry, 34, 62-71.

Fässberg, M. M., Cheung, G., Canetto, S. S., Erlangsen, A., Lapierre, S., Lindner, R., ... \& Duberstein, P. (2016). A systematic review of physical illness, functional disability, and suicidal behaviour among older adults. Aging and Mental Health, 20(2), 166-194. Crossref.

Fiske, A., Wetherell, J. L., \& Gatz, M. (2009). Depression in older adults. Annual Review of Clinical Psychology, 5, 363-389. Crossref.

Forlani, C., Morri, M., Ferrari, B., Dalmonte, E., Menchetti, M., De Ronchi, D. \& Atti, A. R. (2014). Prevalence and gender differences in late-life depression: A population-based study. American Journal of Geriatric Psychiatry, 22, 370-380. Crossref.

Forsman, A. K., Schierenbeck, I., \& Wahlbeck, K. (2011).
Psychosocial interventions for the prevention of depression in older adults: Systematic review and meta-analysis. Journal of Aging and Health, 23(3), 387-416. Crossref.

Garfield, V., Llewellyn, C. H., \& Kumari, M. (2016). The relationship between physical activity, sleep duration and depressive symptoms in older adults: The English Longitudinal Study of Ageing (ELSA). Preventive Medicine Reports, 4, 512-516. Crossref.

Haigh, E. A., Bogucki, O. E., Sigmon, S. T., \& Blazer, D. G. (2018). Depression among older adults: A 20-year update on five common myths and misconceptions. The American Journal of Geriatric Psychiatry, 26(1), 107-122. Crossref.

Hummel, J., Weisbrod, C., Boesch, L., Himpler, K., Hauer, K., Hautzinger, M., ... \& Dutzi, I. (2017). AIDE-acute illness and depression in elderly patients. Cognitive-behavioral group psychotherapy in geriatric patients with comorbid depression: A randomized, controlled trial. Journal of the American Medical Directors Association, 18(4), 341-349. Crossref.

IBM (2017). IBM SPSS Statistics for Windows, Version 25.0. Armonk, NY, USA: IBM Corp.

Lipski, E. (2012). Digestive Wellness: Strengthen the Immune System and Prevent Disease Through Healthy Digestion. New York, NY, USA: McGraw-Hill.

Lue, B. H., Chen, L. J., \& Wu, S. C. (2010). Health, financial stresses, and life satisfaction affecting late-life depression among older adults: A nationwide, longitudinal survey in Taiwan. Archives of Gerontology and Geriatrics, 50, S34-S38. Crossref.

Luppa, M., Sikorski, C., Luck, T., Ehreke, L., Konnopka, A., Wiese, B., ... \& Reidel-Heller, S. G. (2012). Ageand gender-specific prevalence of depression in latest-life: Systematic review and meta-analysis. Journal of Affective Disorders, 136, 212-221. Crossref.

McIntyre, E., Lauche, R., Frawley, J., Sibbritt, D., Reddy, P., \& Adams, J. (2019). Physical activity and depression symptoms in women with chronic illness and the mediating role of health-related quality of life. Journal of Affective Disorders, 252, 294-299. Crossref.

Petkus, A. J., Beam, C. R., Johnson, W., Kaprio, J., Korhonen, T., McGue, M., ... \& IGEMS Consortium. (2017). Gene-environment interplay in depressive symptoms: Moderation by age, sex, and physical illness. Psychological Medicine, 47(10), 1836-1847. Crossref.

Saracino, R. M., Rosenfeld, B., \& Nelson, C. J. (2016). Towards a new conceptualization of depression in 
older adult cancer patients: A review of the literature, Aging and Mental Health. 20(12), 1230-1242. Crossref.

Sagduyu, A. (1997). Depression Scale for Older Individuals: A reliability and validity study compared to the Hamilton Depression Scale [Yaşlılar için Depresyon ölçeği: Hamilton Depresyon Ölçeği ile karşılaştırmalı güvenilirlik ve geçerlilik çalışması]. Turkish Journal of Psychiatry, 8(1), 3-8.

Subramaniam, M., Abdin, E., Sambasivam, R., Vaingankar, J. A., Picco, L., Pang, S., ... \& Chong, S. A. (2016). Prevalence of depression among older adults: Results from the well-being of the Singapore elderly study. Annals Academy of Medicine Singapore, 45, 123-33.
Yen, I. H., Michael, Y. L., \& Perdue, L. (2009). Neighborhood environment in studies of health of older adults: A systematic review. American Journal of Preventive Medicine, 37(5), 455-463.

Yesevage, J. A., Brink, T. L., Rose, T. L., Lum, O., Huang, V., Adey, M., \& Leirer, V. O. (1983). Development and validation of a geriatric depression screening scale: A preliminary report. Journal of Psychiatric Research, 17(1), 37-49. Crossref.

Zivin, K., Llewellyn, D. J., Lang, I. A., Vijan, S., Kabeto, M. U., Miller, E. M., \& Langa, K. M. (2010). Depression among older adults in the United States and England. The American Journal of Geriatric Psychiatry, 18(11), 1036-1044. Crossref. 